\title{
New public health approaches to end-of-life care
}

Authors: Libby Sallnow (1) and Sally Paul (2)

(1) Palliative Care Physician, University College London Hospital, London UK

(2) Lecturer, School of Social Work and Social Policy, University of Strathclyde, Glasgow UK

\section{End-of-life care in need of new public health approaches}

The palliative and end-of-life care movement worldwide has been a success story in many respects. Palliative care services exist in many countries throughout the world and are increasingly integrated into mainstream health services. The plight of those dying in pain has been highlighted as a human rights issue at both national and global levels (Knaul et al. 2017) and the impact of early palliative care is increasingly recognised in certain disease groups (Temel et al. 2010).

Despite these achievements, the movement continues to face challenges from demographic trends, changing patterns of illness and social contexts of care which suggest increasing need for services. Further to this, the movement is increasingly facing criticisms that the original vision of holistic care is being interpreted in a more restrictive manner, focusing on physical or psychological symptoms at the expense of social concerns. The proliferation of professionals in the discipline has led some to reflect that communities no longer feel confident or able to respond to end of life issues, depending increasingly on professional responses which both disempower people and place further demands on services.

One response to these concerns has been to redefine how end-of-life care is understood. Rather than holding it as a medical issue, under the remit of health and social care professionals, it should be reframed as a social experience. This then allows individuals, families and communities to take an active role in the issues affecting them, working with professional services to meet the needs of the dying. This approach of working in partnership with communities is named the new public health approach to end-of-life care.

This chapter will begin by detailing the emergence of the new public health movement and the key documents that have shaped its development. It will go on to discuss the relevance of a new public health approach to end-of-life care, identifying key theoretical models that seek to develop and conceptualise this area of practice. It finishes by highlighting examples of new public health approaches to end-of-life care to illustrate the different ways in which this approach is being used in practice. 


\section{An introduction to new public health}

The new public health movement emerged in the later part of the 20th century. Whilst it emerged from and built on the traditional or classical public health movement of centuries before, the movement was 'new' in that it challenged and redefined certain components of the approach. New public health continued to endorse many aspects such as the role of policy in improving health and the importance of prevention of disease or ill-health, but it also represented a departure from classical public health, through its radical reframing of health as everyone's responsibility. This included identifying the importance of the social determinants of health alongside biomedical factors and the positioning of patients, carers, communities and citizens as experts in their own health. New public health approaches have equity as their core focus and seek to bring healthy lives within everyone's reach. As a result they take a much broader view of the causes and solutions for health and wellbeing, going beyond medicine, biomedical approaches and professional responses.

Fran Baum, in her book "The New Public Health" (2015), describes five innovative features of a new public health approach (see Box 1).

Box 1: Features of a new public health approach:

1. Puts the pursuit of equity at the centre of public health endeavours

2. Is based on the assumption that social and environmental factors are responsible for much ill health

3. Argues for health-promoting health services that are based on a strong system of primary health care

4. Stresses the role of all sectors in impacting on health and the importance of health in all policies

5. Stresses the importance of participation and involvement in all new public health endeavours

As the new public health approach was formalised, it galvanised a range of different approaches from pre-existing global movements such as community development, behavioural, health education and environmental approaches and indigenous and lay medicine. This has led to a diverse and inclusive field.

\subsection{Key documents that have shaped the new public health}

A series of documents and declarations have helped define the field of new public health.

1) The so-called Lalonde Report, after the then-ruling Canadian Health Minister, was published in 1974 (formally titled "A new perspective on the health of Canadians") 
and provided an important articulation of the broad range of factors, beyond the biomedical health care system, understood to influence and determine health. It recognised the role of environmental, political, lifestyle factors and healthcare services, through the health field concept (Lalonde, 1974).

2) The Alma-Ata Declaration, published by the World Health Organization (WHO) in 1978, positioned primary healthcare as participatory health care, in which people have both a right and a duty to participate. It provided a new model for affordable, sustainable and universal primary health care (see Box 2: An excerpt from The AlmaAta Declaration).

3) The Ottawa Charter for Health Promotion (World Health Organisation 1986) (see Box 3 ) defined the new practice of health promotion as the process of enabling people to increase control over, and to improve their health. Whilst it has provided a framework for a new public health approach globally, there have been some criticisms voiced over the extent to which it incorporates the diversity of perspectives globally, focusing on individual rather than collective approaches to health (MacPhail-Bell et al., 2013).

Box 2: An excerpt from The Alma-Ata Declaration (WHO 1978)

Primary health care is essential health care based on practical, scientifically sound and socially acceptable methods and technology made universally accessible to individuals and families in the community through their full participation and at a cost that the community and country can afford to maintain at every stage of their development in the spirit of self-reliance and self-determination.

Box 3: The Ottawa Charter for Health Promotion (WHO 1986): the five pillars

1. Building healthy public policy

2. Creating supportive environments

3. Strengthening community action

4. Developing personal skills

5. Re-orienting healthcare services toward prevention of illness and promotion of health

Subsequent documents from the WHO have further embedded this approach, including the Millennium Development Goals and the subsequent Sustainable Development Goals (Sachs, 2012) but new public health approaches go beyond the WHO principles. Much grassroots community action can be considered under the umbrella term of new public health approaches. The balance of power between such local and informal initiatives and those supported by healthcare organisations and institutions continues to inform, challenge and redefine the field.

\section{New public health approaches and end-of-life care}


The hospice and palliative care movement has made great strides in challenging the conditions in which the dying and their close family are cared for and supported. It is argued, however, that these movements are have become predominantly a professional or service-based response and this has led to over-professionalisation of care and a disempowerment of communities in relation to these issues (Kellehear 2005). Further concerns have been raised regarding the inequity of care provided at the end-of-life (Dixon et al., 2015) or the international variation (Economist Intelligence Unit, 2015). The predicted demographic changes, relating to rising numbers of older people and the prevalence of chronic illness, will place further stress on the system (Etkind et al., 2017).

For these reasons, alternative approaches to supporting death, dying, loss and care can offer more holistic, empowering and sustainable models of support. The new public health approach to end-of-life care integrates principles of health promotion, equity, social and environmental responses to ill health and professional/lay power sharing and partnerships. The broad natures of both new public health and end-of-life care have meant that a range of examples is in existence today. The two common terms used to describe these approaches are health promoting palliative care and compassionate communities.

Health promoting palliative care describes the application of the five pillars of health promotion to end-of-life care (Kellehear 1999). It aims to change the practice of endof-life care and provides a structure for services to develop health promoting practices. This model focuses heavily on the role of professional services and the subsequent movement of compassionate communities moves beyond end-of-life care services to look at the role lay communities, schools, businesses or councils play in end-of-life care.

One of the key principles of new public health is working with communities as partners, often termed community engagement and defined by the authors as:

'an umbrella terms for a process which enables communities to work together to understand, build capacity and address issues to improve their experience of end-of-life and bereavement and related wellbeing. It exists on a spectrum of engagement that extends from informing through to empowering, depending on a range of factors such as the degree of participation from the local community and the intention of the work. Community engagement activities in end-of-life care services go beyond working in the community to working with the community to improve the experiences of end-of-life care'. (Sallnow and Paul, 2015) 


\section{Current practices in end-of-life care}

Examples of new public health approaches to end-of-life care are developing around the world and represent a diverse set of approaches, shaped both in response to local need and the differing approaches contained within the new public health field. Such work includes, but is not limited to: mobilising existing or facilitated community networks and/or resources; working with community organisations to influence perceptions of and responses to death and bereavement; awareness raising, education and/or training activities around specific end-of-life issues; and policy reform (Sallnow et al. 2016). The significance of these activities for meaningful endof-life care, and the challenge of applying a new way of thinking to this area of practice, has resulted in a number of frameworks that attempt to define and develop how new public health approaches to end-of-life care are conceptualised and how they are different to service delivery approaches.

\subsection{The theory: what defines a new public health project?}

Allan Kellehear's (2005 p.156) 'Big Seven Checklist' offers a guide to understanding 'genuine' health promoting palliative care activities (see Box 4). It highlights the significance of community ownership, collaboration and participation in employing a health promoting approach to end-of-life care. The checklist also identifies the importance of developing activities that are based on early intervention and harmreduction that involves normalising death, dying and bereavement: proactively preparing individuals and communities for related experiences.

\section{Box 4: The Big Seven Checklist}

1. In what way does the project help prevent social difficulties around death, dying, loss or care?

2. In what way do they harm-minimise difficulties we may not be able to prevent around death, dying, loss or care?

3. In what ways can these activities be understood as early interventions along the journey of death, dying, loss or care?

4. In what ways do these activities alter/change a setting or environment for the better in terms of our present or future responses to death, dying, loss or care?

5. In what way are the proposed activities participatory - borne, partnered and nurtured by community member? 
6. How sustainable will the activities or programmes be without your future input?

7. How can we evaluate their success of usefulness so that we can justify their presence, their funding and their ongoing support?

The Spectrum for Community Engagement in End-of-Life Care (Sallnow and Paul 2015) offers a framework for end-of-life care service providers to both understand and develop new public health approaches (see Box 5). It employs a hierarchical model that represents five types of work along a continuum involving different levels of power sharing and participation. This extends from informing the people or communities that they work with, to consulting with them, co-producing, collaborating and finally empowering them. The spectrum thus distinguishes a new public health approach from more traditional forms of service provision by placing emphasis on the development of community capacity and resilience.

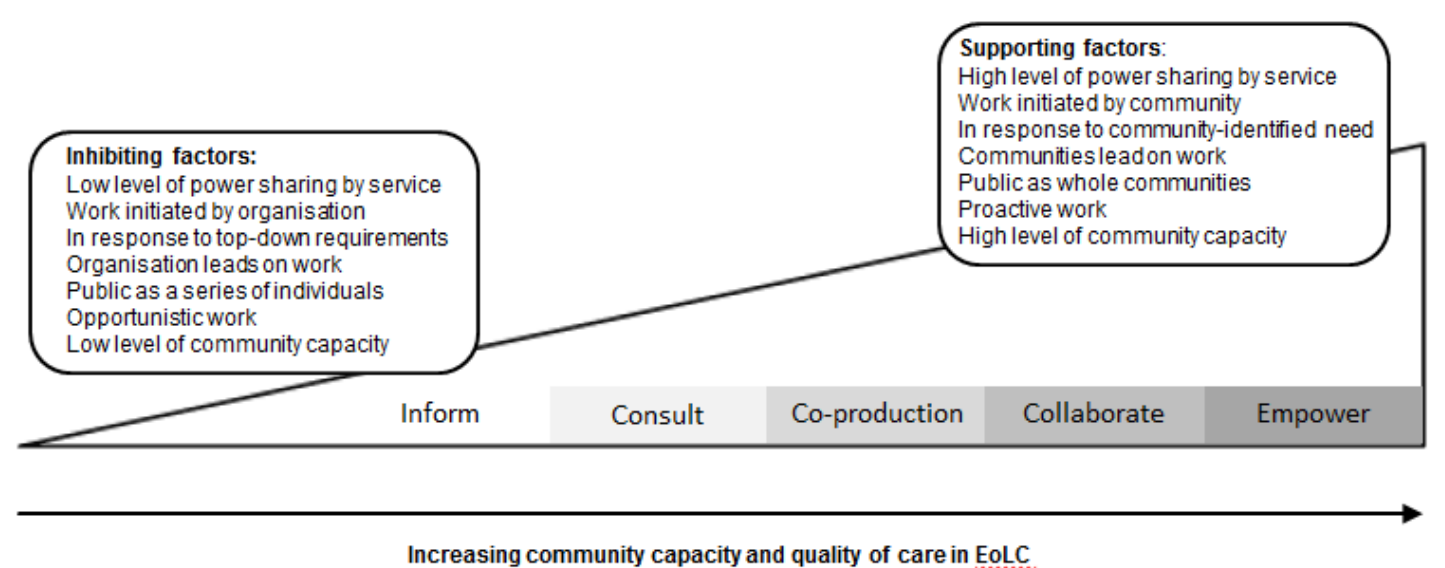

Box 5: The Spectrum for Community Engagement in End-of-Life Care: Developing community capacity [EoLC - End-of-life care].

Reproduced with permission: Sallnow L., Paul S., (2015) Understanding community engagement in end-of-life care: developing conceptual clarity, Critical Public Health, 25(2), 231-238. Taylor and Francis Ltd www.tandfonline.com

4.2: Practice: examples of existing new public health approaches in end-oflife care 
This section discusses four existing practice examples that are illustrative of new public health approaches to end-of-life care. It follows the earlier theoretical sections by exploring what these approaches look like in practice and how they have been understood and evaluated.

\section{A. Example One: Compassionate Neighbours, London}

The Compassionate Neighbours project recruits and trains local people to become Compassionate Neighbours. Compassionate Neighbours are local people who support those nearing the end of their lives in their own homes. The project focuses on supporting people to be good neighbours rather than training them in a new role. The aim is to support those at the end of life and their families through companionship, practical support, connecting people to their communities or helping people to access services they need.

Recruitment is through a series of open days that culminate in a selection day, where participants select whether they would like to participate in the project and the project managers determine if there are any reasons they may not participate. Once enrolled in the project, participants complete a training course. This is either over four full days or over two weekends. Approximately 15 participants take part in each training programme. At the end of the training programme, a DBS (Disclosure and Barring Service) check is carried out. The project managers and Compassionate Neighbour then jointly consider the roles most appropriate for them. For some, they are matched with people in the community immediately, but for others, a different role within the project is selected. Not everyone begins with being matched to someone in the community; some participate in other aspects of the project and some are never matched yet remain with the project. The focus is less on matching set numbers of people but instead on developing the capacity of members of the community to make their own contribution.

The project holds supportive and reflective monthly meetings for all Compassionate Neighbours. In these meetings, participants can reflect on their relationship with the person they are visiting but are also encouraged to reflect on themselves and their own personal development. These are based on a model of personal and group learning and are termed practice development meetings (PDM). In addition to these more formal modes of support, the project hosts a weekly coffee morning in a public space in the hospice open to all participants and the general public. These meetings allow people to come and learn about the project and for the Compassionate Neighbours to meet with each other and develop the network of peer support. Internal and external speakers come and speak about topics related to the project 
such as how to support someone with dementia, or can be of general relevance, such as managing fuel poverty.

The project has developed to have over 200 trained Compassionate Neighbours matched with over 90 people in the community at the time of writing and has won many prestigious national awards. It has two full time members of staff coordinating the project and although initially set up outside the traditional volunteer department, is working increasingly closely with it today.

The project has been the subject of a mixed methods evaluation (Sallnow et al., 2017). The study showed how participating in the project improved participants sense of wellbeing, connection and feelings of loneliness. Interestingly, although those being visited at the end of life described these changes, the most significant changes were observed for the Compassionate Neighbours. Their membership of a large network, the time taken to develop new skills and make new friends and the development of a sense of meaning and purpose was seen to have the most significant impact. These outcomes illustrate how this functioned as a new public health project, acting to prevent and reduce social isolation and disconnection in people before they reached the end of life. The outcomes for those training were seen as important as those receiving the care, illustrating how this sits distinctly from a service-based approach focusing only on outcomes for the recipient.

\section{B. Example Two: Work with Schools, Central Scotland}

Strathcarron Hospice, in Stirlingshire, Scotland, undertook an action research study to identify how Hospice staff could work with schools in their catchment area. This was because the Hospice catchment area covered 160 schools and received numerous adhoc requests from schools for: pre and post bereavement support for pupils; education sessions relating to end-of-life care; and presentations on the role of the Hospice due to local fundraising initiatives. The study therefore aimed to explore how the Hospice could work with these schools in a more structured and meaningful way that involved advancing education and support around end-of-life and bereavement care. Through a process that involved working in partnership with staff, parents and children aged 9 to 12 , several practice developments were identified that were found to be useful for the school curriculum and the relationship between hospices and school communities (Paul et al 2016). Four activities were subsequently co-created, piloted and then delivered as part of normal service delivery at both the Hospice and participating schools. These innovations include:

- The Resilience Project - an education programme for all 9-12 year olds that aims to: introduce death as a normal part of the lifecycle; develop an understanding of what happens to the body at death; nurture the skills and capacity of children to cope when someone dies; and support an awareness of 
other people's needs when someone dies and how to respond appropriately. The programme is delivered over five core lessons but is adapted according to the needs, and questions, of each group of children.

- Bereavement training to school staff - a two-hour free training session that is offered to all schools in the Hospice catchment area. It seeks to assist staff to develop confidence and skills in engaging and supporting children experiencing bereavement whilst also dispel myths associated with hospice care and ensure that any referrals for specialist bereavement support are appropriate.

- Hospice information leaflets - children and Hospice staff co-designed a leaflet that explains the role of the Hospice in the community. This leaflet is included in all Hospice fundraising materials that are sent to/used with schools so that school staff are able to communicate to children what the Hospice does in an age appropriate way.

- A Schools Bereavement Policy - a document sent to all schools that provides a framework for school staff on what to do if a child and/or staff member is bereaved. The policy seeks to support staff to feel more confident when dealing with bereavement experiences and where to access appropriate support and resources if needed.

These practice innovations sit apart from the Hospices previous work with schools as they do not involve the Hospice delivering specific services but mobilising those involved in caring for children to be actively involved in providing support and education around hospice, end-of-life and bereavement care. The learning about what these activities means for Hospices in working with school communities is outlined in Box 6.

Box 6: Role of the Hospice in working with schools: a model for integrated practice Reproduced with permission: Paul S., Cree V., Murray S.A. (2016) Integrating palliative care into the community: the role of hospices and schools. BMJ Supportive and Palliative Care, Published online 11 August 2016

\begin{tabular}{|l|l|l|}
\hline Role of Hospice & Goal & Practice innovation(s) \\
\hline Awareness Raising & $\begin{array}{l}\text { Dispel myths associated with } \\
\text { hospice care, end-of-life care } \\
\text { and bereavement. }\end{array}$ & $\begin{array}{l}\text { Develop existing } \\
\text { fundraising campaigns } \\
\text { that focus on raising } \\
\text { awareness of hospice } \\
\text { care. }\end{array}$ \\
\hline $\begin{array}{l}\text { Education and } \\
\text { training }\end{array}$ & $\begin{array}{l}\text { Increase awareness of } \\
\text { childhood bereavement. } \\
\text { Develop capacity of school staff } \\
\text { to manage childhood } \\
\text { bereavement within the school } \\
\text { setting and at home. }\end{array}$ & $\begin{array}{l}\text { Plan and deliver } \\
\text { bereavement training for } \\
\text { school staff }\end{array}$ \\
\hline
\end{tabular}




\begin{tabular}{|l|l|l|}
\hline $\begin{array}{l}\text { Leadership in death } \\
\text { education and } \\
\text { bereavement }\end{array}$ & $\begin{array}{l}\text { Influence policy makers and/or } \\
\text { management teams to establish } \\
\text { death, dying and bereavement } \\
\text { affirming activities, policies and } \\
\text { procedures. }\end{array}$ & $\begin{array}{l}\text { Engage with school } \\
\text { communities to raise } \\
\text { awareness of palliative } \\
\text { care issues. } \\
\text { Work with school staff to } \\
\text { develop a death and life- } \\
\text { affirming curriculum. } \\
\text { Work with school staff to } \\
\text { develop bereavement } \\
\text { policies and procedures. }\end{array}$ \\
\end{tabular}

\section{Example Three: Compassionate City Charter}

The Compassionate City Charter focuses on sectors of society outside traditional palliative care or even health and social care services. The reason for this is the potential hit-and-miss nature of services developed by discrete community interests or services, where some communities may be involved whilst others are unaware of projects. The Compassionate City Charter takes a civic approach by developing a programme of work through local governments, mayors offices or other municipal agencies and engaging broadly with all the cultural, religious, commercial or leisure organisations in a locality, both to engage with a broader part of the local community, but also to explicitly situate issues around death and dying as outside the remit of health and social care. It then becomes everybody's business.

Kellehear (2016) has outlined the steps a local government should take to develop their local area as a compassionate city (See Box 4).

Box 4: The Compassionate City Charter (Kellehear, 2016)

Compassionate Cities are communities that recognise that all natural cycles of sickness and health, birth and death, and love and loss occur every day within the orbits of its institutions and regular activities. A Compassionate City is a community that recognises that care for one another at times of crisis and loss is not simply a task solely for health and social services but is everyone's responsibility.

Compassionate Cities are communities that publicly encourage, facilitate, support and celebrate care for one another during life's most testing moments and experiences, especially those pertaining to life-threatening and life-limiting illness, chronic disability, frail, ageing and dementia, death in childhood, grief and bereavement, and the trials and burdens of long term care. Though local government strives to maintain and strengthen quality services for the most fragile and vulnerable in our midst, those persons are not the limits of our experience of fragility and vulnerability. Serious personal crises of illness, dying, death and loss may visit any us, at any time during the 
normal course of our lives. A compassionate city is a community that squarely recognises and addresses this social fact.

Through the auspices of the Mayor's office or equivalent body, a compassionate city will by public marketing and advertising, by use of the city's network and influences, by virtue of collaboration and co-operation, in partnership with social media and its own offices - develop and support the following 13 social changes to the cities key institutions and activities.

1. Our schools will have annually reviewed policies or guidance documents for dying, death, loss and care.

2. Our workplaces will have annually reviewed policies or guidance documents for dying, death, loss and care.

3. Our trade unions will have annually reviewed policies or guidance documents for dying, death, loss and care.

4. Our places of worship will have at least one dedicated group for end-of-life care support.

5. Our city's hospices and nursing homes will have a community development program involving local area citizens in end-of-life care activities and programmes.

6. Our city's major museums and art galleries will hold annual exhibitions on the experiences of ageing, dying, death, loss or care.

7. Our city will host an annual peacetime memorial parade representing the major sectors of human loss outside military campaigns - cancer, motor neuron disease, AIDS, child loss, suicide survivors, animal companion loss, widowhood, industrial and vehicle accidents, the loss of emergency workers and all end-of-life care personnel, etc.

8. Our city will create an incentives scheme to celebrate and highlight the most creative compassionate organisation, event, and individual/s. The scheme will take the form of an annual award administered by a committee drawn from the end-of-life care sector. A 'Mayors Prize' will recognise individual/s for that year who most exemplify the city's values of compassionate care.

9. Our city will publicly showcase, in print and in social media, our local government policies, services, funding opportunities, partnerships, and public events that address 'our compassionate concerns' with living with ageing, life threatening and life-limiting illness, loss and bereavement, and long term caring. All end-of-life care-related services within the city limits will be encouraged to distribute this material or these web links including veterinarians and funeral organisations.

10.Our city will work with local social or print media to encourage an annual citywide short story or art competition that helps raise awareness of ageing, dying, death, loss, or caring.

11.All our compassionate policies and services, and in the policies and practices of our official compassionate partners and alliances, will demonstrate an understanding of 
how diversity shapes the experience of ageing, dying, death, loss and care - through ethnic, religious, gendered, and sexual identity and through the social experiences of poverty, inequality, and disenfranchisement.

12.We will seek to encourage and to invite evidence that institutions for the homeless and the imprisoned have support plans in place for end-of-life care and loss and bereavement.

13.Our city will establish and review these targets and goals in the first two year and thereafter will add one more sector annually to our action plans for a compassionate city - e.g. hospitals, further and higher education, charities, community \& voluntary organizations, police \& emergency services, and so on.

\section{Example Four: To Absent Friends Festival, Scotland}

To Absent Friends, a People's Festival of Storytelling and Remembrance is a Scotlandwide event that is held on the $1-7^{\text {th }}$ November each year. The festival was initiated by the Scottish Partnership for Palliative Care, through the Good Life, Good Death, Good Grief Alliance, and aims to empower Scottish society to re-assert control of death in their own lives by making it acceptable to share memories and stories of people who have died. The festival has a number of supporters but is not owned by one particular group, instead it seeks to provide an opportunity for individuals and groups to remember people who have died in whatever way is meaningful for them and their communities, in public or private.

Since the first festival in 2014 the range and breadth of activities have expanded and now occur across Scotland. Patterson and colleagues (2017) detail some of these activities that include:

- Public events that are open to all, such as concerts, storytelling and poetry events

- Community events that are run by organizations for their own members and invitees, such as activities ran by local hospices, nursing homes and charitable organisations that encourage the sharing of memories

- Private events that are held by individuals, families and groups of friends, such as making memory boxes, lighting remembrance candles and visiting cemeteries

- Online activities, such as using the festival website to dedicate music videos or leave messages on the wall of remembrance

The festival has been subject to an evaluation that identified its potential to engage people from a variety of social and economic communities (Scottish Partnership for Palliative Care 2015). This evaluation also identified that the success of the festival was related to local ownership of the events. The time, knowledge and skills of the Scottish Partnership for Palliative Care in growing the festival was also highlighted yet 
this time was viewed as necessary in supporting the promotion of activities that would, in turn, generate wider participation.

\section{Summary}

This chapter has explored the emergence of new public approaches to end-of-life care and their establishment as an integral component of end-of-life care for the future. The range of approaches that have evolved recognise the diversity of need that exists for individuals, families, communities and society when faced with issues relating to death, dying, loss and care: a new public health approach represents a broad an inclusive model for meeting these needs collectively. Four practice examples have been provided that identify the breadth of the approach but by no means define the scope, as projects must be locally relevant and tailored. Such activities sit apart from traditional, clinical based, service delivery approaches by working with communities as equal partners to identify and respond to their own end-of-life and bereavement needs. 


\section{References}

Baum, F., 2015. The New Public Health 4th ed., Melbourne: Oxford University Press

Beattie, A., 1991. Knowledge and control in health promotion: a test case for social policy and social theory, in J. Gabe, M. Calnan, \& M. Bury, eds. The Sociology of the Health Service.,London: Routledge

Dixon J.,King, D., Matosevic, T., Clark, M., Knapp, M., 2015. Equity in the Provision of Palliative Care in the UK: Review of Evidence, London: London School of Econois and Political Science

Economist Intelligence Unit, 2015. The 2015 Quality of Death Index, London

Kellehear, A., 1999. Health Promoting Palliative Care. Melbourne, Oxford University Press

Kellehear, A., 2005. Compassionate Cities, London: Routledge

Kellehear, A., 2016. The Compassionate City Charter: inviting the cultural and social sectors into end of life care. In Compassionate Communities: Case Studies from Britain and Europe, Oxon: Routledge, pp. 76-87.

Knaul, F.M., Farmer P.E., Krakauer E.L., De Lima, L., Bhadelia, A., Kwete, X.J., et al., 2017. Alleviating the access abyss in palliative care and pain relief - an imperative of universal health coverage: The Lancet Commission report. DOI: https://doi.org/10.1016/S0140-6736(17)32513-8

Lalonde, M., 1974. A new perspective on the health of Canadians. Ottawa, ON: Minister of Supply and Services Canada. Retrieved from Public Health Agency of Canada website: http://www.phac-aspc.gc.ca/ph-sp/pdf/perspect-eng.pdf

McPhail-Bell, K., Fredericks, B. \& Brough, M., 2013. Beyond the accolades: a postcolonial critique of the foundations of the Ottawa Charter. Global Health Promotion, 20(2), pp.22-29

Sachs J.E., 2012. From Millennium Development Goals to Sustainable Development Goals. Lancet, 379: 2206-11 
Sallnow L., Richardson H., Murray S.A., Kellehear A., 2016. The impact of a new public health approach to end-of-life care: a systematic review. Palliative Medicine, 30(3) 200-211

Sallnow L., Richardson H., Murray S.A., Kellehear A., 2017. Understanding the impact of a new public health approach to end-of-life care: a qualitative study of a community led intervention, Lancet, 389 s88

Sallnow L., Paul S., (2015) Understanding community engagement in end-of-life care: developing conceptual clarity, Critical Public Health, 25(2), 231-238

Scottish Partnership for Palliative Care (2015) To Absent Friends, a people's festival of storytelling and remembrance: activity and evaluation report, Edinburgh: SPPC

Patterson R., Peacock, R., Hazelwood, M. (2017) To Absent Friends, a people's festival of storytelling and remembrance, Bereavement Care, 36(3), 119 - 126

Paul S., Cree V., Murray S.A. (2016) Integrating palliative care into the community: the role of hospices and schools. BMJ Supportive and Palliative Care, Published online 11 August 2016

Temel J.S., Greer JA., Muzikansky, A., Gallagher E.R., Admane S., Jackson V.A., et al., 2010 Early Palliative Care for Patients with Early Non-Small Cell Lung Cancer. NEJM 363:733-742

WHO-UNICEF, 1978. Primary health care. A joint Report by the Director General of the World Health Organization and the Executive Director of the United Nations Children's Fund, New York: WHO

World Health Organisation, 1986. The Ottawa Charter for Health Promotion, Ottawa: WHO/Canadian Public Health Association/Health Canada 